\title{
Optimising child and adolescent health and development through an integrated ecological life course approach
}

\author{
Fully realising the potential of children and adolescents will require an ecological life course \\ approach, together with multisectoral, coordinated, integrated action for the provision of \\ care and services for children and adolescents, argue Mark Tomlinson and colleagues
}

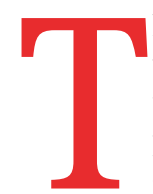

he past 25 years have seen unprecedented global reductions in under 5 mortality. ${ }^{1}$ This progress reflects the commitment of governments, international agencies, and funders as part of efforts to achieve the millennium development goals, as well as global economic improvements. However, despite overall success, progress has been uneven. Increasingly, there have been calls to broaden the way in which child health investments are made-most notably the sustainable development goals and the Global Strategy for Women's, Children's, and Adolescents' Health. ${ }^{2}$ Both shift the focus explicitly to multisectoral, coordinated, integrated action to support child and adolescent health.

One of the pillars of the global strategy is that of "thrive," defined in the strategy as "ensuring health and well-being." Unlike "surviving," thriving cannot be measured with a single indicator; it is an ongoing process across the life course from

\section{KEY MESSAGES}

- Unlike "surviving," thriving cannot be measured with a single indicator but is an ongoing process across the life course

- An ecological life course perspective highlights how what happens to a child at each developmental stage is shaped and influenced by what has happened in earlier stages

- Discrete interventions, targeting a single issue and developmental period are essential, but they must be complemented by programmes targeting other influences, such as physical environment, policy, and institutions

- Children and adolescents meeting their developmental potential must be realised through enabling environments across the life course conception and continues until the end of adolescence. ${ }^{3}$ Making the shift from a single indicator at one time point (eg, under 5 mortality) to a conceptual understanding of the determinants of child and adolescent health across the life course is essential. In this paper we argue that an integrated ecological life course approach provides one way of linking risk and protective factors over time, capturing the social determinants of health. We describe what extending the concept of nurturing carethe conditions that enable communities and caregivers to ensure child health and nutrition, and protect them from threatsacross the life course might look like, and discuss its implications for intervention, including programming, policy, and global health practice.

\section{Integrated ecological life course approach}

A key principle of the WHO Nurturing Care Framework $^{4}$ is that of enabling environments. Enabling environments are created by services, policies, programmes, and communities across the life course. While the framework was originally produced to provide a roadmap for the period from pregnancy to age 3 , creating an enabling environment to ensure children reach their developmental potential ${ }^{5}$ is of lifelong importance.

An ecological framework of health and development is not new to the study of child development, but we suggest that such a framework has not been routinely employed in the child health field. Ecological models frame individual development as occurring within concentric circles of influence radiating out from the individual, including the child and the family and community, as well as institutional, policy, and environmental levels of influence. Some models denote the levels as micro, meso, and macro, or individual, community, and society. Figure 1 uses such an ecological graphic to show how demographic, economic, neighbourhood, environmental, social, and cultural factors exert influence on human health, through factors that are close to the individual (proximal-eg, housing density, housing insecurity) and those whose influence is more indirect (distaleg, urbanisation, national policies). ${ }^{6}$

There is a synergy between ecological and life course approaches to child health and development. Life course approaches complement ecological models in describing how individual life experiences are shaped by their immediate and extended environments, by adding the dimension of time, showing how current child and adolescent functioning depends in part on past exposures and experiences. An ecological life course model encourages us to think about development as a process that is cumulative and continuous, and cautions against approaches to programming that silo risks or age groups or that view children and adolescents in narrow "disease model" terms. ${ }^{7}$ In ecological life course perspectives, what happens to a child at each developmental stage is shaped and influenced by what has happened in all earlier stages. Child and adolescent health and development are interdependent and consecutive, with progress in one period being shaped by influences and events in preceding periods. In addition, an integrated ecological life course approach implies that intervention efforts should be different for different populations, determined by the unique combinations of risk and protective factors to which they are currently, and have previously been, exposed.

At the individual level, much is known about the relation between risk and protective factors and health and development outcomes. However, there is a social gradient for risk and protective factors, as well as outcomes. The concepts of biological embedding and 


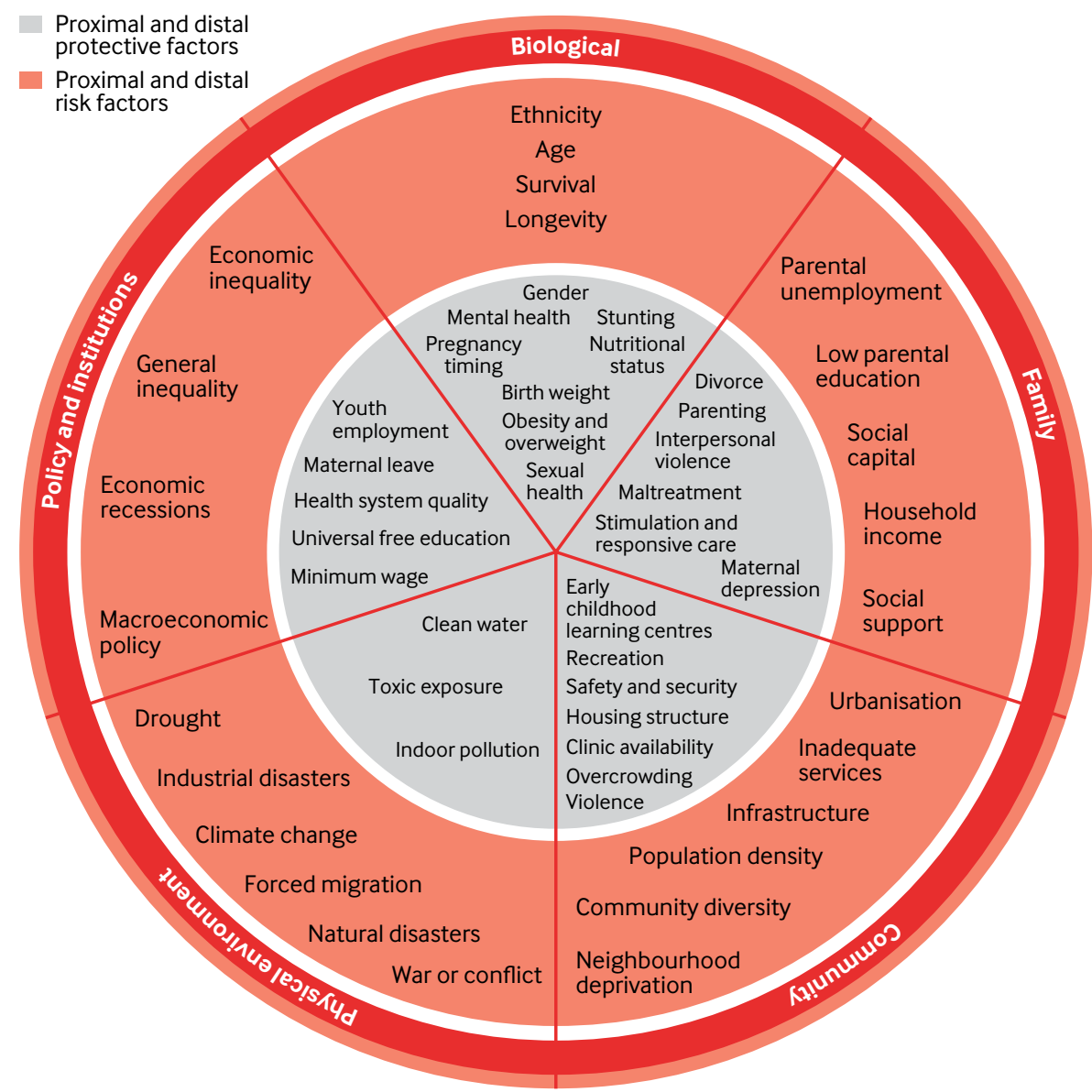

Fig 1 | Proximal and distal risk factors in a life course ecological approach (adapted from Lund et $\mathrm{al}^{6}$ )

developmental cascades (see definitions in box 1) describe the mechanisms by which social gradients in health and illness come to exist within an individual-how they get "under the skin." 8 One example is that low socioeconomic status is a risk factor for exposure to violence. Children exposed to violence early in life may embed (through neurological factors and endocrinology) a heightened sensitivity to danger cues in the environment. A child with anxiety may then enter school, develop further internalising symptoms, be distracted from work, and receive low grades. This hypothetical child is then more likely to remain in a low socioeconomic environment, as options for employment are curtailed by educational failure.

Children living in adversity are also surrounded by a host of protective factors, such as nurturing parental care, strong social support networks, and rich early learning environments, and as a result may have totally different trajectories. In addition, even without early buffering factors, a negative life course trajectory is not set in stone. Changes in the proximal environment (availability of a nurturing caregiver, changes in employment status) or the distal environment (government provision of clean water, safe play areas, or a new primary health clinic in a rural area) may shift the trajectory.

Giving consideration to social determinants and the role of early environments in later outcomes is not meant to be deterministic. Many children living in highly vulnerable settings can still achieve their full health and developmental potential provided they, and their families, are adequately supported.

\section{Implications for intervention}

The ecological life course perspective prioritises a focus on environmental exposures and concentrates on mechanisms, pathways, and the interaction between risk and protective factors over time. By recognising the ecological nature of development, we are led invariably to prioritising multisectoral interventions. For example, if education targets are to be met, child nutrition must be adequate and child health services need to reach the most vulnerable and be of good quality. If gender equality is to be achieved, community violence must be prevented. And if community violence is to be prevented, early education, positive parenting in the early years, and targeted interventions for at-risk school age children must all be in place. All of this needs to happen in a context where policies create an enabling environment.

Much of the focus of global health interventions to date has concentrated on single diseases or issues (that is, a siloed approach) and often at a single point in a child's life. It is clear that these interventions are essential and vital for child survival, and that relatively discrete interventions remain key to tackling time bound influences on child health, such as immunisations and treatment for sick children. However, a siloed approach is an inadequate response to the complexity of child and adolescent health and development. While relatively discrete interventions, targeting a single issue and developmental period at a single level of the child's ecology, are essential (box 2), interventions that target 


\section{Box 1: Definitions}

Ecological framework-Framework that considers the systems in which humans are embedded rather than in isolation from context

Enabling environments-The systems, forces, and factors that create the conditions in which optimal child and adolescent development is possible

Life course perspective-Acknowledgment that each stage of development builds on the last, focusing on the full continuum of development from preconception through adolescence and beyond

Biological embedding-Early developmental contexts cause stable epigenetic modifications in the individual and these modifications endure, shaping how the individual responds to subsequent exposures over the life course

Developmental cascade-Early functioning in one domain of behaviour or emotional functioning spills over to influence other domains

the concentric rings of influence in the child's ecological environment are also necessary (fig 1). Integrated nutrition and responsive caregiving interventions ${ }^{9}$ as well as family centred approaches to HIV prevention, treatment, care, and support programmes, ${ }^{10}$ are good examples of more holistic or ecological approaches.

We need an approach that commits to a consideration of enabling environments and that reaches beyond the sphere of the individual child to tackle core determinants of health and wellbeing, and-by extension-inequities. Important questions that such an approach must consider include the possibility of offsetting negative events in one developmental phase (for instance, malnutrition in infancy) with targeted interventions in a later developmental phase (such as integrated nutrition and responsive caregiving interventions in early childhood or prevention and promotion of adolescent mental health problems) further on in the life course.

Implicit in the case we are making is the understanding that while interventions in the early years are key and are regarded as the most cost effective, ${ }^{11}$ bolstering these with additional interventions later in development to reinforce early gains is essential. There is substantial literature showing that early gains are not necessarily maintained and that some waning of beneficial effects is common. ${ }^{12}$ In contexts of high adversity, despite excellent protection, prevention, and treatment efforts, many children will need early gains to be reinforced, bolstered, and "topped up" if early benefits are to be maintained and to accrue. Just as ensuring that children survive does not guarantee that they will thrive, providing optimal nurturing care in the first 1000 days is not an inoculation against later adversity. This is a concern for the millions of children who live in humanitarian settings and who commonly face insecurity, lack of access to services, and suboptimal living conditions. Currently, one in five babies globally is born into a setting characterised by conflict. ${ }^{13}$ Protecting their developmental trajectories throughout their childhood by provision of enabling environments that deal with the physical and mental health and

wellbeing of both caregivers and children is essential to restore stability, security, and safety and mitigate the harmful effects that displacement and violence have on communities, families, and ultimately children's lives.

Child and adolescent potential must be realised through enabling environments across the life course. While few data are available on the long term impact of interventions delivered in the perinatal period, for example, it is possible to ensure that early gains from the provision of infant and young child survival and early child development interventions are bolstered and reinforced by subsequent interventions through childhood and adolescence. This may take a variety of forms such as quality early education centres and schools; programmes that create opportunities for children and adolescents who are not in school; and making communities safe for children, adolescents, and their families. It should also include policies that equip communities, families, and caregivers with

\section{Box 2: Examples of life course interventions and policies}

Biological and psychosocial interventions

- Antenatal, childbirth, and postnatal care

- HIV prevention and care

- Nutrition

- Responsive care

- Immunisation

- Management of childhood illness

- Physical activity

- Adolescent friendly sexual and reproductive health services

- Adolescent and caregiver mental health

- Care for developmental delays, disorders, and disabilities

- Injury prevention

Supportive policies

- Minimum wage

- Universal healthcare

- Maternity protection

- Food safety and labelling

- Affordable child care

- Universal access to education

- Sexual and reproductive rights

- Road safety regulations

- Tobacco and alcohol taxation

- Family friendly workplace policies

- Social protection schemes

Supportive physical environment

- Clean water

- Adequate sanitation

- Clean air

- Clean energy

- Environments free of toxins

- Secure places for recreation

- Safe roads

- Smoke-free public spaces

- Child friendly urban design 
time and resources to provide responsive childcare, and that ensure safe, clean, and secure environments for children to grow and develop.

Achieving the sustainable development goals will require an ecological life course approach to the provision of care and services for children and adolescents. The targets call for multisectoral engagement and sustained, supportive programmes and interventions. The focus on disease and tendency towards siloed models in the millennium development goals was understandable given the magnitude of the disease burden and the large numbers of children dying before the age of 5 . However, the new sustainable development goals era necessitates an approach where protection, prevention, and treatment approaches work synergistically, ensuring that gains made in early childhood are reinforced at later ages. As all these are interlinked and interdependent, it requires that all sectors and groups working with particular age groups not only cooperate but also actively build on areas of common influence to create the conditions for children and adolescents to flourish across the life course. $^{14}$

Contributors and sources: MT, XH, and BD conceived the outline of this paper and drafted the first version. FO reviewed and revised a second draft of the paper. $\mathrm{MT}, \mathrm{XH}, \mathrm{BD}, \mathrm{NR}, \mathrm{DR}$, and FO reviewed and revised drafts of the manuscript, and MT and XH created the final version. This paper is drawn from a background paper prepared in support of the WHO/UNICEF expert consultation Redesigning Child and Adolescent Health Programming for the SDG Era, WHO, Geneva, 23-25 January 2019.

Competing interests: We have read and understood BMJ policy on declaration of interests and have no relevant interests to declare.

Provenance and peer review: Commissioned; externally peer reviewed.
This article is part of a series proposed by WHO and Unicef and commissioned by The BMJ, which peer reviewed, edited, and made the decision to publish. Article handling fees, including open access are funded by WHO and Unicef.

Mark Tomlinson, professor ${ }^{1,2}$

Xanthe Hunt, senior researcher ${ }^{1}$

Bernadette Daelmans, public health specialist ${ }^{3}$

Nigel Rollins, child health specialist ${ }^{3}$

David Ross, professor ${ }^{3}$

Frank Oberklaid, professor ${ }^{4}$

${ }^{1}$ Institute for Life Course Health Research, Department of Global Health, Stellenbosch University, South Africa ${ }^{2}$ School of Nursing and Midwifery, Queen's University, Belfast, UK

${ }^{3}$ Department of Maternal, Newborn, Child, Adolescent Health, and Aging, World Health Organization,

Geneva, Switzerland

${ }^{4}$ Centre for Community Child Health, Royal Children's Hospital and Murdoch Children's Research Institute, Melbourne, Australia

Correspondence to: Mark Tomlinson,

markt@sun.ac.za

Check for updates

This is an Open Access article distributed under the terms of the Creative Commons Attribution IGO License (https://creativecommons.org/licenses/ by-nc/3.0/igo/), which permits use, distribution, and reproduction for non-commercial purposes in any medium, provided the original work is properly cited.

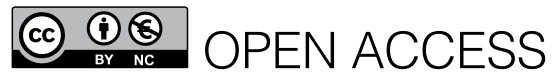

1 United Nations Inter-agency Group for Child Mortality Estimation. Levels and trends in child mortality: report 2019. Estimates developed by the United Nations Inter-agency Group for Child Mortality Estimation. United Nations Children's Fund, 2019.

2 United Nations. The Global Strategy for Women's, Children's and Adolescents' Health. United Nations, 2015: 2016-30.

3 Tomlinson M, Ross DA, Bahl R, et al. What will it take for children and adolescents to thrive? The Global Strategy for Women's, Children's, and Adolescents' Health. Lancet Child Adolesc Health 2019;3:208-9. doi:10.1016/S2352-4642(19)30004-5
4 World Health Organization. Nurturing care for early childhood development: a framework for helping children survive and thrive to transform health and human potential. WHO, 2018.

5 Grantham-McGregor S, Cheung YB, Cueto S, Glewwe P, Richter L, Strupp B, International Child Development Steering Group. Developmental potential in the first 5 years for children in developing countries. Lancet 2007;369:60-70. doi:10.1016/S0140-6736(07)60032-4

6 Lund C, Brooke-Sumner C, Baingana F, et al. Social determinants of mental disorders and the sustainable development goals: a systematic review of reviews. Lancet Psychiatry 2018;5:357-69. doi:10.1016/S2215-0366(18)30060-9

7 Blane D, Netuveli G, Stone J. The development of life course epidemiology. Rev Epidemiol Sante Publique 2007;55:31-8. doi:10.1016/j. respe.2006.12.004

8 Hertzman C, Boyce T. How experience gets under the skin to create gradients in developmental health. Annu Rev Public Health 2010;31:329-47, 3p, 347.

9 Yousafzai AK, Obradović J, Rasheed MA, et al. Effects of responsive stimulation and nutrition interventions on children's development and growth at age 4 years in a disadvantaged population in Pakistan: a longitudinal follow-up of a clusterrandomised factorial effectiveness trial. Lancet Glob Health 2016;4:e548-58. doi:10.1016/S2214109X(16)30100-0

10 Rochat TJ, Bland R, Coovadia H, Stein A, Newell ML. Towards a family-centered approach to HIV treatment and care for HIV-exposed children, their mothers and their families in poorly resourced settings. Future Virol 2011;6:687-96. doi:10.2217/fvl.11.45

11 Heckman IJ. Skill formation and the economics of investing in disadvantaged children. Science 2006;312:1900-2. doi:10.1126/ science.1128898

12 Bailey D, Duncan GJ, Odgers CL, Yu W. Persistence and fadeout in the impacts of child and adolescent interventions. J Res Educ Eff 2017;10:7-39. doi:10.1 080/19345747.2016.1232459

13 United Nations Children's Fund. 29 million babies born into conflict in 2018. UNICEF, 2019.

14 Shonkoff JP, Garner AS, Committee on Psychosocial Aspects of Child and Family Health, Committee on Early Childhood, Adoption, and Dependent Care, Section on Developmental and Behavioral Pediatrics. The lifelong effects of early childhood adversity and toxic stress. Pediatrics 2012;129:e232-46. doi:10.1542/peds.2011-2663

Cite this as: BMJ 2021;372:m4784

http://dx.doi.org/10.1136/bmj.m4784 